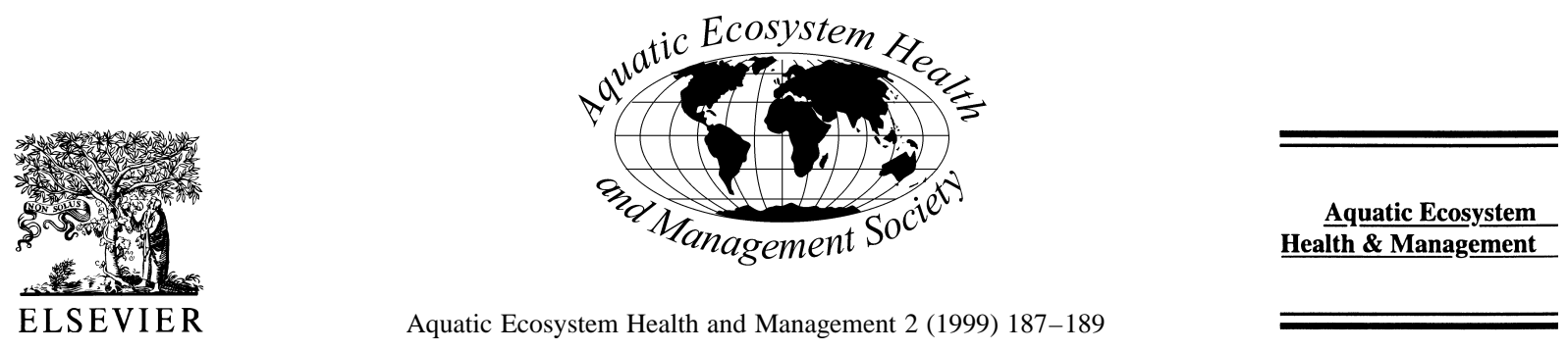

\title{
The implementation of a regional biomonitoring program in northeast Brazil
}

\author{
T. Watanabe ${ }^{\text {a,* }}$, R.A. Coler ${ }^{\mathrm{a}}$, R.J. Paz \\ ${ }^{a}$ Departamento de Sistemática e Ecologia, Centro de Ciências Exatas e da Natureza, Universidade Federal da Paraíba, $58051-900$ João \\ Pessoa, PB, Brazil \\ ${ }^{\mathrm{b}}$ Programa Regional de Pós-Graduação em Desenvolvimento e Meio Ambiente, Centro de Ciências Exatas e da Natureza, Universidade \\ Federal da Paraíba, Caixa Postal 5063, 58051-970 João Pessoa, PB, Brazil
}

\begin{abstract}
A methodology to inventory water quality in northeast Brazil through biomonitoring is described. Essentially the methodology is based on the United States Environmental Protection Agency protocol supplemented by benthic macroinvertebrate diversity data. To date six test species have been selected to represent the overall aquatic biota response to different pollutants: the snail (Pomacea linetata), fish (Molienesia sp.), prawn (Macrobrachium amazonicum), zooplankton (Daphnia similis), macrophytes (Lemna sp.) and periphytic algae (Selenastrum capricornutum). These organisms will be exposed to test waters and evaluated with regard to acute toxicity (survival) and chronic toxicity (photosynthesis, respiration, excretion, growth and reproduction).

An extensive training program has been set-up. Regional governmental laboratories and staff will be equipped with the capacity to conduct bioassays routinely. Training and research activities are housed in the Environmental Management laboratories at the Federal Technical School of Paraíba, as well as at the Federal University of Paraíba, Campus I, Systematic and Ecology Department. (C) 1999 Elsevier Science Ltd and AEHMS. All rights reserved.
\end{abstract}

Keywords: Bioassay; Toxicity; Water quality; Indicator organisms; Pesticide pollution; Watershed management

\section{Introduction}

Threatened by its diminishing reserves of potable and ecologically healthy waters, northeast Brazil is confronted with an emerging ecological/public health crisis, because water impoundments are almost without exception exploited for irrigation and human consumption. Shortly after the great drought of 1877-1879 when 500000 people perished, the government adopted measures to increase storage capacity of surface waters. Consequently, the majority of existing reservoirs were built some 90 years ago.

\footnotetext{
* Corresponding author.

E-mail address: watanabe@dse.ufpb.br (T. Watanabe)
}

Paradoxically, despite their fundamental importance it is not known how many dams have been constructed in the northeast of Brazil. The Integrated Study of Hydrological Resources of the Northeast Project (PEIRHINE) calculates (via Landsat photos) the number of dams to be between 50000 and 60000 . However, this estimate rose to 70000 when impoundments with an area in excess of $1000 \mathrm{~m}^{2}$ were included (Molle, 1991). These numbers alone underscore the immense social significance of these dams.

Unfortunately, water quality monitoring and maintenance has not received the same level of attention. To date, the subject of agrotoxin and fertilizer contamination of aquatic ecosystems in northeast Brazil has not been presented at any national or 
international conference. In many reservoirs, strong faecal contamination has compromised water potability (Ceballos et al., 1995). Intensive applications of agrotoxins and fertilizers on steeply tilled soils coupled with intensive rainfall conspire to produce runoff and inundation of the cultivated land. At the commencement of the rainy season, pollutants from this run-off can be extremely stressful to an aquatic ecosystem. The impact of this pollution is greatly influenced by the agrotoxin used and the temperature and dilution of run-off. These observations however are largely based on supposition.

We are faced then with a crisis of ignorance that could prove costly. We know that the fertilizers, pesticides and heavy metals applied to the water shed can be carried to the reservoir by runoff erosion and rising water levels during the rainy season. We neither know how mobile these pesticides are nor the extent to which dilution and degradation of the pesticide molecule would offset toxicity. Further, we have neither the economy nor the expertise and instrumentation (atomic absorption, gas chromatography and so on) to monitor these impoundments.

Fortunately an alternative approach (Bioassay) has evolved. To date no toxicological data have been generated on the inland waters of northeast Brazil. Our overall objective is to amass such a data base in recognition of the impending crisis and to develop remedial strategies for sustainable agriculture and aquaculture.

\section{A regional biomonitoring program}

In the past 20 years the water pollution control agencies of the USA and Europe have come to recognize that ecological standards for environmental quality must be founded on biological parameters. As pollution is fundamentally a biological problem, a 'parts per million' perspective often fails to provide the true dimension of an environmental insult. Mere presence does not indicate biological availability nor does it integrate and predict total biological impact through synergistic and antagonistic interactions. However, statistically and biologically significant data can be consistently generated at a fraction of the cost of a chemical analytical laboratory. Any routine wet chemistry laboratory could include this capacity.

The Federal University of Paraíba (UFPB) and the Federal Technical School of Paraíba (ETFPB) have jointly launched a training program to routinely monitor waters in rivers, pools or holding tanks. Three specific objectives will be implemented:

1) State and federal water quality technicians will be trained in the practice of toxicity testing. These people will serve as a network to gather baseline toxicity data on the principal water bodies in their district. The accumulated data will serve as a reference point to recognize early trends, impacts of industrial and municipal activities and evaluate efficacy of implemented remedial measures.

2) A sampling and testing protocol applicable to impoundments throughout the northeast of Brazil will be evolved. The intent here is to avoid inconsistencies among laboratories.

3) The impact of specific farming practices will be evaluated (e.g. such parameters as proximity to water, frequency of herbicide application and steepness of cultivated land will be studied with respect to impacts).

In this context, a laboratory has been designated at ETFPB in the Environmental Technology Department not only to process water samples but to serve as a training facility as well. The laboratory will be staffed by faculty and students from the ETFPB and UFPB. Upon graduation, ETFPB students will be funneled into the UFPB Systematics and Ecology Department to continue their training.

The first class is comprised of the participating faculty from ETFPB and UFPB graduate students. The course will consist of a $40 \mathrm{~h}$ laboratory-lecture training program to provide basic theory and skills in toxicity testing. The laboratories are in place and functioning. Our first class, presently in session, includes four graduate students (MS candidates) and four faculty from the ETFPB. Subsequently, a more applied and less theoretical training experience will be offered to those technicians employed in federal and state water laboratories. The federal training labs are the Brazilian Institute of Environment and Renewable Natural Resources (IBAMA) and the National Drought Management Department (DNOCS). The state laboratories are the Water and Sewage Company of Paraíba (CAGEPA) and the Environment 
Management Superintendency (SUDEMA). After training, the participation will staff a state wide monitoring network, working to identify acutely toxic impoundments.

Epitácio Pessoa Reservoir (Bouqueirão Municipality) has been tentatively selected as a typical site that will serve to refine techniques and define sampling strategies. The reservoir supports approximately 600 farmers, each with a variety of crops, it would be logistically impossible to set-up as many sampling stations. Consequently, two to three sampling stations will be selected on the lake periphery and the sampling strategy will be based on the 'worst case' scenario of the farms. These worst case parameters include: (a) the steepest angle of run-off; (b) a history of the most intensive application (concentration and frequency) of pesticides and fertilizers and (c) crops cultivated close to the lake's edge.

Sampling will begin early in the rainy season when dilution is low and soil residue concentrations are at their highest. Water samples will be taken from runoff, interflow and the lake margins. Artificial substrates will be deployed for six weeks in the lakes at the selected sites and at others, which are the least intensively farmed (to serve as control sites). The intent here is to generate diversity indices that will provide further indications of habitat suitability. In this manner, field testing will make relevant the replicated controlled laboratory data generated by toxicity testing.

Samples from suspect water bodies will be modified to meet the alkalinity, hardness and $\mathrm{pH}$ requirements of Daphnia and the nutritional prerequisites of Lemna. Subsequently, these samples will be tested for toxicity with Daphnia, fish (residual oxygen method) and Lemna (Eaton et al., 1995; Macek, 1984). These biological-screening tests will permit rapid processing of samples. If the rapid screening indicates the tested material is acutely toxic, tests will continue with the full complement of test organisms to determine $\mathrm{LC}_{50}$ 's (that concentration required to kill $50 \%$ of the organisms in $96 \mathrm{~h}$ ) and $\mathrm{EC}_{50}$ 's (that concentration required to diminish some life function by $50 \%$ of the control levels).

Testing will continue throughout the rainy season to determine if and to what extent toxicity diminishes with time. After six weeks substrates will be retrieved from the control and test sites to determine the Brillouin Diversity Index (Pratt, 1981). If no acute toxicity is measured in run-off or lake samples, testing will terminate for that site. Provided there are sufficient resources available, the lake study will be expanded to include routine testing of test species (e.g. prawn and periphyton), artificial substrate diversity comparison, and so on within the lake. The data thus generated would permit us to evaluate toxicity originating from interflow and run-off as a function of distance travelled, rainfall and concentration and frequency of pesticide applied. With these data it may be possible to identify, at least tentatively, maximum allowable toxicant concentrations (MATC) with regard to application frequencies and permissible distances of cultivation from lake's margins. If the data prove consistent, we will procure programming expertise to develop a predictive capacity correlating the toxicological response with rain fall, agrotoxin application rates and land features.

\section{References}

Ceballos, B.S.O., Lima, E.O., Köning, A., Martins, M.T., 1995. Spatial and temporal distribution of fecal coliforms, colifages, moulds and yeasts in freshwater at the semi-arid tropic northeast Brazil (Paraíba state). Rev. Microbiol. São Paulo 26, 90-100.

Eaton, A.D., Clesceri, L.S., Greenberg, A.E. (Eds.), 1995. Standard Methods for Examination of Water and Wasterwater 19. APHA, AWWA, WEF, Washington.

Macek, K.J., 1984. Effluent evaluation. In: Rand, G.M., Petrucelli, S.R. (Eds.). Fundamentals of Aquatic Toxicology: Methods and Applications, Hemisphere, New York, pp. 636.

Molle, F., 1991. Caracteristiques et potencialités des "aÇudes" du Nordeste Brasilien. PhD Thesis, University of Montpellier II, Montpellier, France.

Pratt, J.M., Coler, R.A., Godfrey, P., 1981. Ecological effects of urban stormwater on benthic macroinvertebrates inhabiting the Green River, Massachusetts. Hydrobiologia 83, 29-42. 